\title{
Serum Interleukin-18 Level is Associated With Disease Activity and Interstitial Lung Disease in Patients With Dermatomyositis
}

\author{
Yuan YANG, ${ }^{1}$ Geng YIN, ${ }^{1}$ Jingcheng HAO, ${ }^{2}$ Qibing XIE, ${ }^{1}$ Yi LIU ${ }^{1}$ \\ ${ }^{1}$ Department of Rheumatology and Immunology, West China Hospital of Sichuan University, Chengdu, China \\ ${ }^{2}$ Department of General, Visceral and Transplantational Surgery, University Hospital of Munich, Campus Grosshardern, Munich, Germany
}

\begin{abstract}
Objectives: This study aims to demonstrate the utilization of serum interleukin-18 (IL-18) level as a biomarker for disease activity and organ damage in patients with dermatomyositis (DM) or polymyositis (PM) using the Myositis Disease Activity Assessment Tool.

Patients and methods: Forty-nine patients (13 males, 36 females) with idiopathic inflammatory myopathies were enrolled in the study. Patients were diagnosed with DM ( $n=33)$ or PM $(n=16)$. Twenty age- and sex-matched healthy volunteers (9 males, 11 females) who were determined to be free of autoimmune disease were included as a control group. Disease activity and organ damage were assessed with Myositis Disease Activity Assessment Tool. Serum IL-18 level was measured with enzyme-linked immunosorbent assay and the differences between patient groups were determined.

Results: The mean ages of DM or PM patients were 44 and 45, respectively. Interstitial lung disease (ILD) was found in 24 patients (48.98\%), including 18 patients with DM (54.55\%) and six patients with PM (37.5\%). There was no significant difference of disease duration between DM patients (17.5 \pm 22.3 months) and PM patients ( $14.9 \pm 28.7$ months). Serum IL-18 level in DM $(669.2 \pm 528.1 \mathrm{pg} / \mathrm{mL}$ ) was significantly higher than that in the control group $(388.3 \pm 139.4 \mathrm{pg} / \mathrm{mL}, \mathrm{p}=0.017)$, but no significant difference was observed between the PM and control group. IL-18 was significantly higher in DM patients with ILD $(890.5 \pm 618.8 \mathrm{pg} / \mathrm{mL})$ than in patients without ILD $(403.8 \pm 84.8 \mathrm{pg} / \mathrm{mL}, \mathrm{p}=0.003)$. It was significantly elevated in patients with severe disease activity $(1001.7 \pm 694.2 \mathrm{pg} / \mathrm{mL})$ than in those with moderate $(485.3 \pm 102.2 \mathrm{pg} / \mathrm{mL})$ or mild disease activity $(421.0 \pm 270.2 \mathrm{pg} / \mathrm{mL})$ $(p=0.039)$. In DM patients, IL-18 was significantly correlated with global disease activity and disease activity in the skin, lung, and heart.

Conclusion: Serum IL-18 level was higher in patients with DM and this was associated with disease activity and ILD complication. Thus, it can be used as a valuable serological marker for DM disease activity and ILD complication.

Keywords: Dermatomyositis; disease activity; interleukin-18; interstitial lung disease; polymyositis.
\end{abstract}

Idiopathic inflammatory myopathies (IIMs) is a heterogeneous group of autoimmune myopathies, characterized by proximal muscle weakness and inflammation of muscles and other organs. ${ }^{1}$ Dermatomyositis (DM) and polymyositis (PM) are the two main types in which the incidence and prevalence of $\mathrm{DM}$ is 1.4 and 5.8 cases per 100,000 persons in a recent study in U.S. with female preponderance and a higher prevalence among older age group, while the prevalence of PM is 9.7 per 100 thousand people. ${ }^{2}$ Despite their different pathological characteristics, both disease types cause muscle inflammation and tissue damage because of deposition of immune complexes, activation of cytokines, and action of adhesion molecules and chemokines. ${ }^{3,4}$

Except for progressive proximal weakness, some patients suffer dyspnea due to interstitial lung disease (ILD) or respiratory muscle weakness, dysphagia related to pharyngeal or esophageal involvement, heart failure or arrhythmia caused by myocarditis, and gastrointestinal bleeding from vasculopathy of the enteron. One of the most common extra muscular involvements is ILD, ${ }^{5}$ an intractable and fatal complication in PM/DM with a prevalence rate of $5-65 \% .{ }^{6}$ More aggressive therapy is required for patients with ILD. 
Therefore, an accurate yet simple predictor is urgently needed in the clinical practice to improve the outcome of DM/PM patients with ILD.

The Myositis Disease Activity Assessment Tool (MDAAT), proposed by the International Myositis Assessment and Clinical Studies Group in $2004,{ }^{7}$ is an assessment tool for disease activity in DM or PM patients, which is now commonly used in clinical practice. However, this tool is thought to be too complicated to use in clinical setting.

Interleukin-18 (IL-18), secreted by antigen presenting cells such as macrophages and dendritic cells, is a T helper 1 (Th1) cytokine which plays an important role in the activation of Th1 immune response. ${ }^{8,9}$ Recent studies showed increased serum IL-18 level in patients with different clinical manifestations of $\mathrm{DM} / \mathrm{PM},{ }^{10}$ especially in those with ILD, ${ }^{11}$ further demonstrating the activation of Th1 immune response in idiopathic inflammatory myopathies. However, the clinical consequences and pathomechanism of elevated serum IL-18 level are still poorly understood. Thus, in this study, we aimed to demonstrate the utilization of serum IL-18 level as a biomarker for disease activity and organ damage in patients with DM or PM using the MDAAT.

\section{PATIENTS AND METHODS}

For this prospective study, 49 adult patients with idiopathic inflammatory myopathies (13 males, 36 females) were recruited in West China Hospital of Sichuan University, China, from August 2014 to December 2014. Patients were diagnosed with DM $(n=33)$ or PM $(n=16)$ according to the Bohan and Peter criteria. ${ }^{12,13}$ Patients with overlapping syndrome and severe mental or somatic disease were excluded. Twenty age- and sex-matched healthy volunteers (9 males, 11 females) who were determined to be free of autoimmune disease were included as a control group. A written informed consent was obtained from each patient. The study was approved by the West China Hospital Ethics Committee and conducted in accordance with the principles of the Declaration of Helsinki.

Interstitial lung disease screening was performed in all patients, in whom lung diseases were not potentially caused by drugs or occupational environmental exposure. Diagnosis was established using comprehensive clinical evaluations and high resolution computed tomography, according to the International Consensus Classification of Interstitial Pneumonias of the American Thoracic Society and the European Respiratory Society. ${ }^{14}$

Myositis Disease Activity Assessment Tool is a comprehensive tool which includes the Myositis Disease Activity Assessment Visual Analog Scales (VASs) (MYOACT) and Myositis Intention to Treat Activities Index (MITAX) assessments. $^{7}$ MYOACT consists of a $10 \mathrm{~cm}$ VAS for six organ systems (constitutional, cutaneous, skeletal, gastrointestinal, pulmonary, and cardiac systems) and is used to determine the overall severity of disease activity, globally and in each system. MYOACT scores range from $0 \mathrm{~cm}$ to $10 \mathrm{~cm}$. Based on their MYOACT global activity VAS score, patients were subdivided into severe, moderate, and mild disease groups. The cutoff points were as follows: $0=$ no disease activity; $1-3=$ mild disease activity; 4-6= moderate disease activity; and $7-10=$ severe disease activity. MITAX assesses specific manifestations in seven organ systems (constitutional, cutaneous, skeletal, gastrointestinal, pulmonary, cardiac, and muscle systems). For MITAX assessment, three to nine criteria related to symptoms, physical findings, or laboratory abnormalities in each of the seven organ systems are assessed and converted into a score that range from zero to nine. The total disease activity score is calculated by summing the score of each organ system. All MDAAT evaluations were performed by a group of experienced and qualified physicians in the Department of Rheumatology and Immunology of the West China Hospital within one week of patient enrollment.

Serum markers, including creatine kinase (CK), aspartate aminotransferase (AST), alanine aminotransferase (ALT), lactate dehydrogenase (LDH), hydroxybutyrate dehydrogenase ( $\mathrm{HBDH})$, erythrocyte sedimentation rate, $\mathrm{C}$-reactive protein, anti-nuclear antibody, and anti-Jo-1 antibody, were measured using standard methods in the Laboratory Department of the West China Hospital. 
Table 1. Demographic and clinical parameters of dermatomyositis and polymyositis groups

\begin{tabular}{|c|c|c|c|c|c|c|c|}
\hline \multirow[b]{2}{*}{ Variables } & \multicolumn{3}{|c|}{ Dermatomyositis group $(n=33)$} & \multicolumn{3}{|c|}{ Polymyositis group (n=16) } & \multirow[b]{2}{*}{$p$} \\
\hline & $\mathrm{n}$ & $\%$ & Mean \pm SD & $\mathrm{n}$ & $\%$ & Mean \pm SD & \\
\hline Age (year) & & & $44 \pm 13$ & & & $45 \pm 17$ & 0.838 \\
\hline Sex & & & & & & & 0.138 \\
\hline Male & 7 & & & 6 & & & \\
\hline Female & 26 & & & 10 & & & \\
\hline C-reactive protein (mg/L) & & & $7.3 \pm 7.1$ & & & $5.2 \pm 6.5$ & 0.983 \\
\hline Erythrocyte sedimentation rate $(\mathrm{mm} / \mathrm{h})$ & & & $35.6 \pm 17.4$ & & & $37.4 \pm 27.3$ & 0.817 \\
\hline Ferritin $(\mathrm{ng} / \mathrm{mL})$ & 7 & & $86.5 \pm 427.4$ & 1 & & 346.0 & 0.769 \\
\hline Creatine kinase (IU/L) & & & $439.5 \pm 1187.3$ & & & $1133.2 \pm 1468.3$ & 0.006 \\
\hline Aspartate aminotransferase (IU/L) & & & $66.2 \pm 87.3$ & & & $78.6 \pm 79.1$ & 0.915 \\
\hline Alanine aminotransferase (IU/L) & & & $67.2 \pm 80.6$ & & & $81.3 \pm 96.9$ & 0.572 \\
\hline Lactate dehydrogenase (IU/L) & & & $324.8 \pm 194.9$ & & & $418.4 \pm 309.8$ & 0.449 \\
\hline Hydroxybutyrate dehydrogenase (IU/L) & & & $264.9 \pm 163.1$ & & & $337.1 \pm 254.6$ & 0.624 \\
\hline Anti-nuclear antibody & 8 & 33 & & 5 & 16 & & 0.602 \\
\hline Anti-Jo-1 & 2 & 33 & & 1 & 16 & & 0.979 \\
\hline
\end{tabular}

Serum IL-18 level was measured by enzymelinked immunosorbent assay (Neobioscience, Shenzhen, Guangdong, China). Briefly, $100 \mu \mathrm{L}$ of samples (diluted 1:5) and standards were placed in a 96-well microplate and incubated at $36{ }^{\circ} \mathrm{C}$ for 90 minutes. The plate was then washed with wash buffer and blocked. Subsequently, $100 \mu \mathrm{L}$ of detection antibody was added into each well and the plate was incubated at $36{ }^{\circ} \mathrm{C}$ for 60 minutes and washed. Following washing, $100 \mu \mathrm{L}$ of streptavidin-horseradish peroxidase was added into each well and the plate was incubated at $36{ }^{\circ} \mathrm{C}$ for 30 minutes in dark. The plate was then washed and $100 \mu \mathrm{L}$ of substrate solution was added into each well. Following an incubation at $36{ }^{\circ} \mathrm{C}$ for 15 minutes, $100 \mu \mathrm{L}$ of stop solution was added into each well. The optical density at $450 \mathrm{~nm}$ was measured using a microplate reader. IL-18 concentrations were calculated based on the optical density values.

\section{Statistical analysis}

Numerical data were presented as the mean \pm standard deviation or as the median. The Spearman rank correlation test was used to determine the association between ranked variables. Continuous data were compared using the Mann-Whitney $\mathrm{U}$ test. All analyses were performed using the IBM SPSS 22.0 statistical software (IBM Corp., Armonk, NY, USA) and Prism 5.0 (GraphPad Software, Inc., La Jolla, CA, USA). $P$ values of $<0.05$ were considered statistically significant.

\section{RESULTS}

Interstitial lung disease was found in 24 patients (48.98\%), including 18 patients with DM (54.55\%) and six patients with PM (37.5\%). There was no significant difference in disease durations between DM patients $(17.5 \pm 22.3$ months) and PM patients (14.9 \pm 28.7 months). Serum markers such as CK, AST, ALT, LDH, HBDH, erythrocyte sedimentation rate, C-reactive protein, antinuclear antibody, and anti-Jo-1 antibody were determined. Among these markers, only the serum CK level was found to be significantly different between the DM $(439.5 \pm 1187.3 \mathrm{IU} / \mathrm{L})$ and PM groups (1133.2 \pm 1468.3 IU/L) ( $p=0.006$; Table 1). Other demographical parameters and laboratory findings were comparable between the DM and PM groups (Table 1).

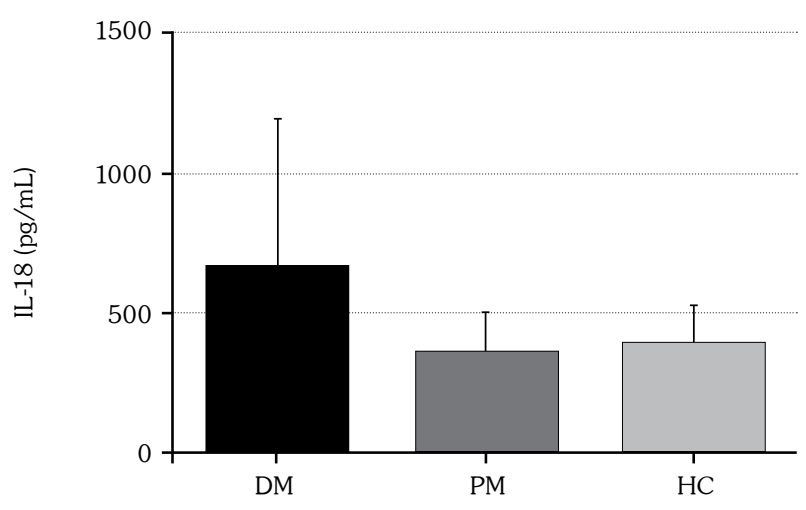

Figure 1. Level of serum interleukin-18 in dermatomyositis, polymyositis, and healthy control groups. DM: Dermatomyositis; PM: Polymyositis; HC: Healthy controls; IL-18: Interleukin-18. 
Serum IL-18 level in DM patients $(669.2 \pm 528.1 \mathrm{pg} / \mathrm{mL})$ was significantly higher than that observed in healthy controls $(388.3 \pm 139.4 \mathrm{pg} / \mathrm{mL}, \mathrm{p}=0.017)$ and PM patients $(361.0 \pm 141.7 \mathrm{pg} / \mathrm{mL}, \mathrm{p}=0.009)$. There was no significant difference in serum IL-18 level between the PM and healthy control groups $(p=0.832$; Figure 1).

DM patients were subgrouped into two based on the presence or absence of accompanying ILD. Serum IL-18 level of the two patient subgroups was compared (Figure 2). The level of IL-18 in DM patients with ILD $(890.5 \pm 618.8 \mathrm{pg} / \mathrm{mL})$ was significantly higher than that observed in DM patients without ILD $(403.8 \pm 84.8 \mathrm{pg} / \mathrm{mL}$, $\mathrm{p}=0.003)$. No significant difference in serum IL-18 level was observed between PM patients with or without accompanying ILD (data not shown).

All DM patients were subdivided into the severe $(n=13)$, moderate $(n=10)$, and mild $(n=10)$ disease groups according to their MYOACT global activity VAS score. Serum IL-18 level in the severe disease group $(1001.7 \pm 694.2 \mathrm{pg} / \mathrm{mL})$ was significantly higher than that of the moderate $(485.3 \pm 102.3 \mathrm{pg} / \mathrm{mL})$ and mild groups $(421.0 \pm 270.2 \mathrm{pg} / \mathrm{mL})(\mathrm{p}=0.039$; Figure 3$)$.

In DM patients, serum IL-18 level was found to be significantly correlated with the global disease activity VAS score $(\mathrm{r}=0.531, \mathrm{p}=0.001)$, MITAX total score $(r=0.481, p=0.005)$, and disease activity of the skin ( $r=0.462, p=0.007)$, lung $(r=0.569$, $p=0.001)$, and heart $(r=0.528, p=0.001)$. In particular, strong positive correlation was observed between the global VAS score and MITAX total

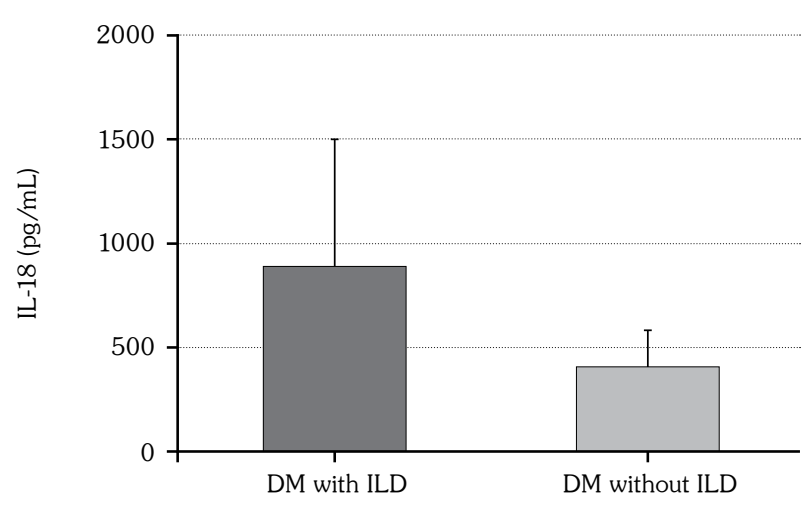

Figure 2. Level of serum interleukin-18 in dermatomyositis patients with and without interstitial lung disease. DM: Dermatomyositis; ILD: Interstitial lung disease; IL-18: Interleukin-18. score $(r=0.859, p<0.0005)$. The two scores were also found to be correlated with the level of $\mathrm{CK}$ ( $\mathrm{r} 1=0.398, \mathrm{p} 1=0.022 ; \mathrm{r} 2=0.415, \mathrm{p} 2=0.016)$, AST ( $\mathrm{r} 1=0.625, \mathrm{p} 1<0.0005 ; \mathrm{r} 2=0.586, \mathrm{p} 2<0.0005)$, $\operatorname{ALT}(\mathrm{r} 1=0.537, \mathrm{p} 1=0.001 ; \mathrm{r} 2=0.479, \mathrm{p} 2=0.005)$, $\mathrm{LDH}(\mathrm{r} 1=0.371, \mathrm{p} 1=0.009 ; \mathrm{r} 2=0.446, \mathrm{p} 2=0.009)$, and $\mathrm{HBDH}$ ( $\mathrm{r} 1=0.419$, p1 $=0.015 ; \mathrm{r} 2=0.390$, $\mathrm{p} 2=0.025$ ). In addition, disease activity of the lung was significantly correlated with the level of $\mathrm{CK}(\mathrm{r}=0.453, \mathrm{p}=0.008)$, AST $(\mathrm{r}=0.564, \mathrm{p}=0.001)$, ALT $(r=0.444, \quad p=0.010), \quad$ LDH $\quad(r=0.529$, $\mathrm{p}=0.002)$, HBDH $(\mathrm{r}=0.453, \mathrm{p}=0.008)$, and antiJo-1 ( $r=0.379, p=0.032)$ (Table 2 and Figure 4-6). In contrast, no such associations were found in PM patients (data not shown).

\section{DISCUSSION}

Autoimmune mechanisms are thought to play important roles in the pathogenesis of both DM and PM. ${ }^{15}$ This may be caused by the imbalance in T-helper cell cytokine levels, ${ }^{16}$ which has been shown to cause high production of both tumor necrosis factor-alpha and interferon-gamma during muscle inflammation. ${ }^{17}$ IL-18 is a Th1 cytokine that contributes to the activation of Th1 immune response. IL-18 is a member of the IL- 1 family and secreted by antigen presenting cells. IL-18 also contributes to the regulation of the IL-18/IL-18R pathway and was shown to be associated with the clinical symptoms of DM and PM.,89

In our study, serum IL-18 level was found to be significantly elevated in patients with DM when compared to those with PM or healthy

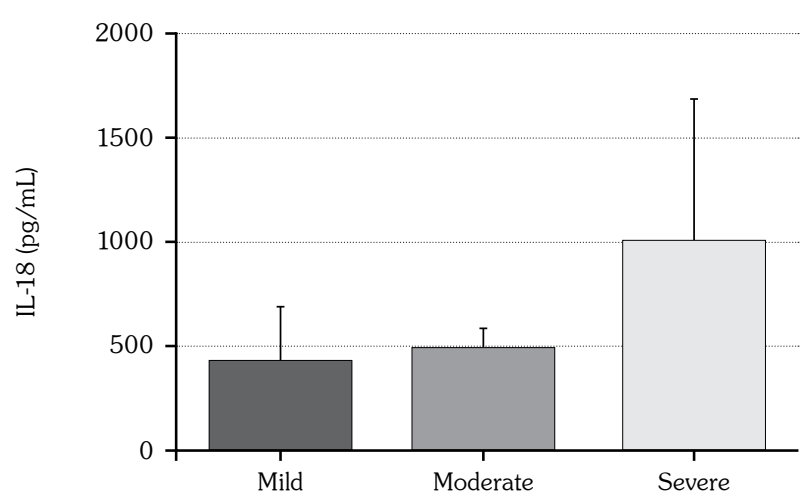

Figure 3. Level of serum interleukin-18 among mild, moderate, and severe disease activity groups in dermatomyositis patients. IL-18: Interleukin-18. 


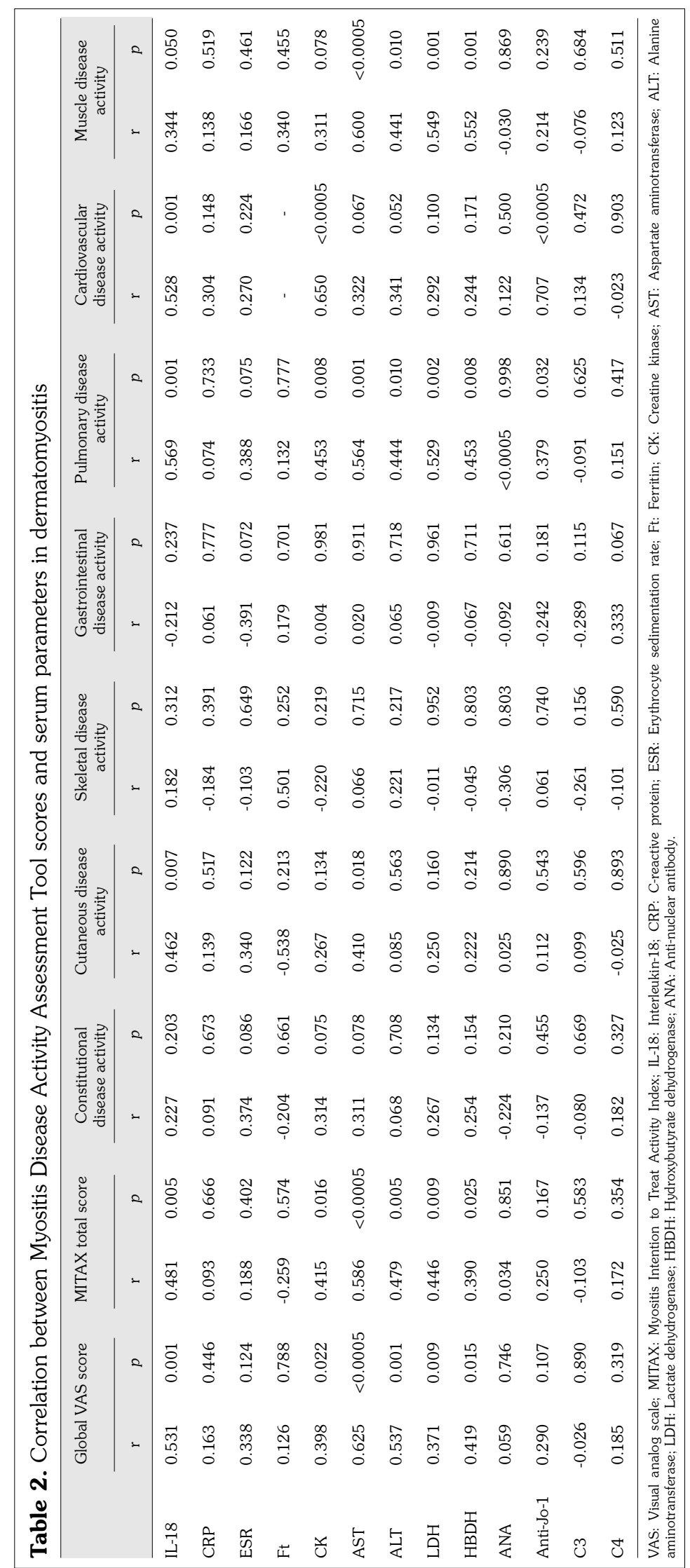




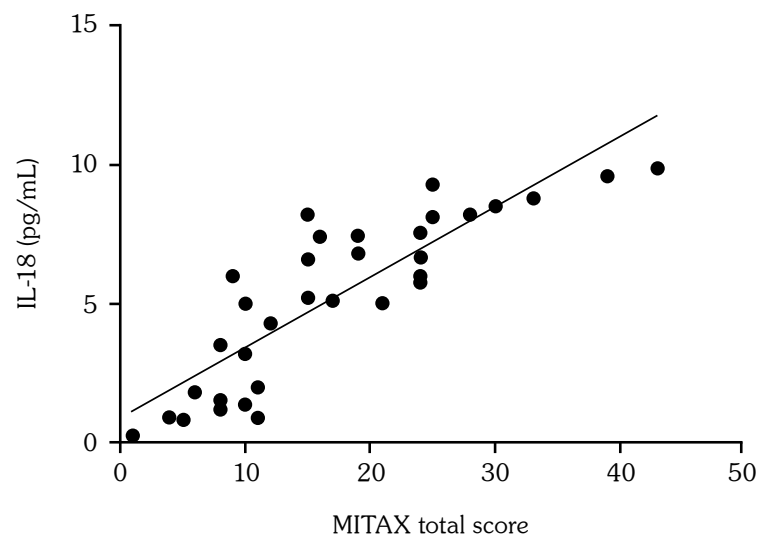

Figure 4. Correlation between global visual analog scale score and Myositis Intention to Treat Activities Index total score in dermatomyositis patients.

individuals. The level was particularly high in DM patients with severe disease, in agreement with a previous report by Gono et al. ${ }^{11}$ However, we did not observe any significant difference in IL-18 level between the PM and control groups. This finding differs from a previous study that demonstrated increased IL-18 in patients with PM. ${ }^{10}$ Furthermore, we found that serum IL-18 level was positively correlated with disease activity in patients with DM, based on the MDAAT assessment which includes the MYOACT global disease activity score and
MITAX disease activity total score. No such correlations were found in patients with PM. This finding is in agreement with a study by Shen et al. ${ }^{18}$ which also demonstrated serum IL-18 association with disease activity in DM, but not in PM patients. Thus, our results indicated that IL-18 plays more important roles in the pathogenesis of DM than PM, and can be considered as a serological maker for DM disease activity. In contrast, IL-18 role in PM could not be established in present study.

Interstitial lung disease, one of the most common complications of DM/PM, is a key factor that determines the prognosis of the patients. ${ }^{19}$ The mortality rate increases by $20-60 \%$ when ILD is found in DM/PM patients. ${ }^{20,21}$ In this study, serum IL-18 level was found to be higher in DM patients with ILD than in those without ILD. Meanwhile, serum markers such as CK, AST, ALT, LDH, HBDH, and anti-Jo-1 were also found to be strongly correlated with the presence of ILD in DM patients. These findings may be explained by a series of pathological processes mediated by activated alveolar macrophages. These cells produce leukotriene B4 and IL-8 in response to high serum IL-18 concentration and stimulate neutrophils to induce lung fibrosis. ${ }^{22-24}$ Previous study in mice demonstrated that IL-2 and IL-18 were responsible for the induction of ILD via
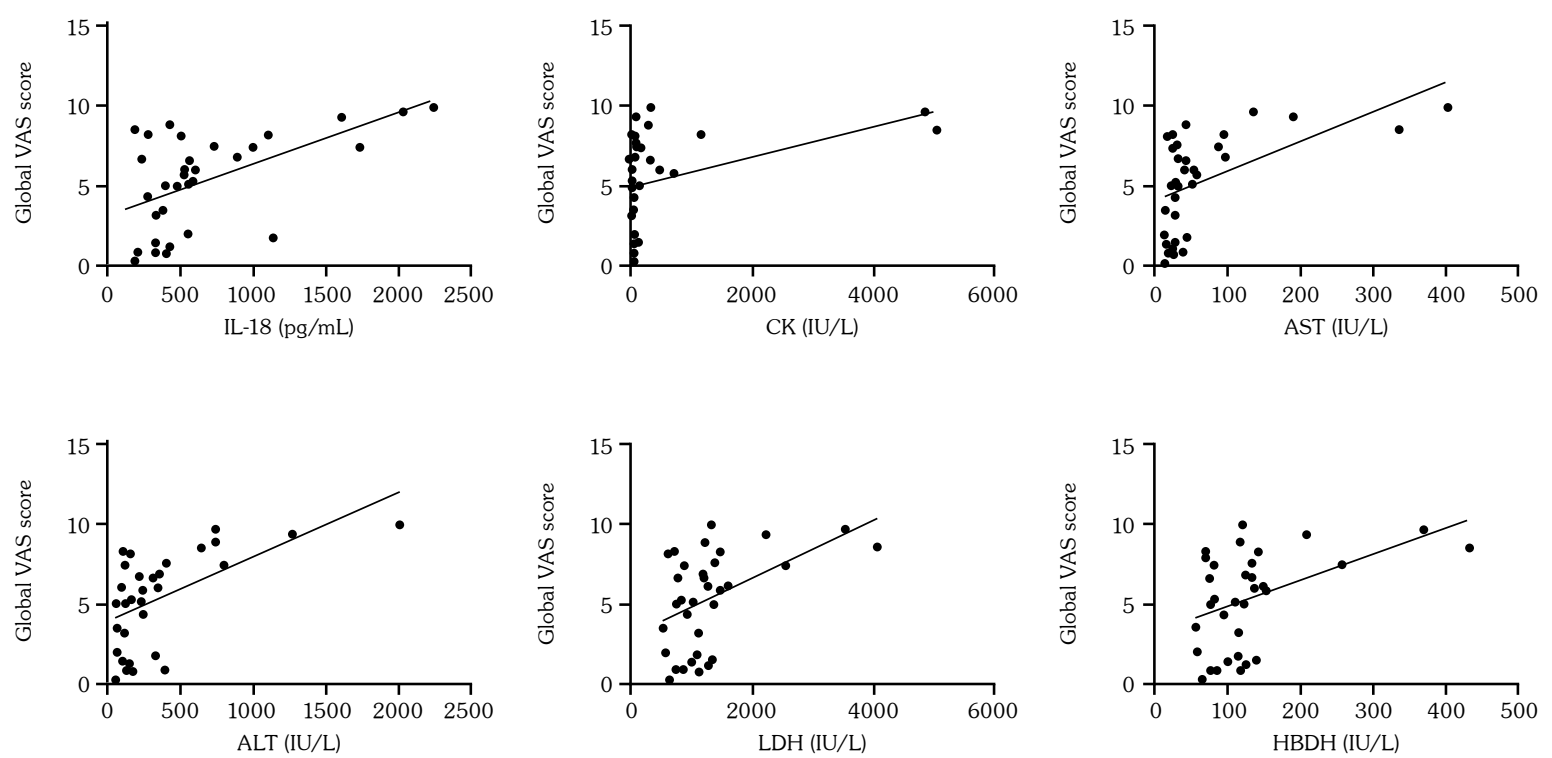

Figure 5. Correlation between global visual analog scale score and each serum parameters in dermatomyositis patients. VAS: Visual analog scale; IL-18: Interleukin-18; CK: Creatine kinase; AST: Aspartate aminotransferase; ALT: Alanine aminotransferase; LDH: Lactate dehydrogenase; HBDH: Hydroxybutyrate dehydrogenas. 

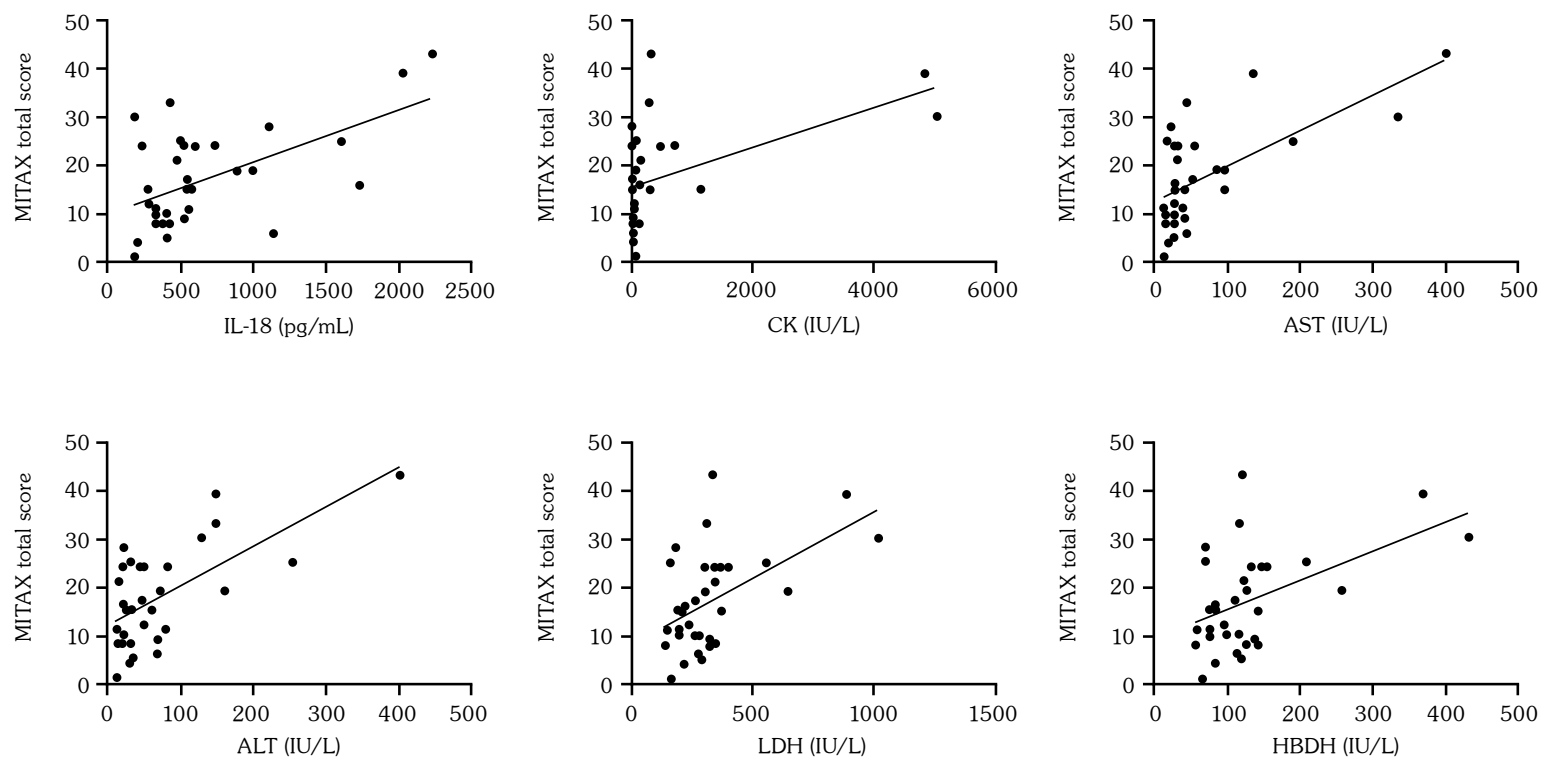

Figure 6. Correlation between Myositis Intention to Treat Activities Index total score and each serum parameters in dermatomyositis patients. MITAX: Myositis Intention to Treat Activities Index; IL-18: Interleukin-18; CK: Creatine kinase; AST: Aspartate aminotransferase; ALT: Alanine aminotransferase; LDH: Lactate dehydrogenase; HBDH: Hydroxybutyrate dehydrogenase.

interferon-gamma production, ${ }^{25}$ demonstrating IL-18 role in the pathogenesis of ILD. We were unable to establish a correlation between serum IL-18 level and ILD in patients with PM. This is consistent with a previous study that also found no difference in serum IL-18 in PM patients with or without accompanying ILD. ${ }^{11}$ Our results suggest that IL-18 plays greater roles in the induction of ILD in DM when compared to PM patients, and IL-18 can be used as a serum marker for DM patients with ILD.

A limitation of our study is the small sample size of PM patients with ILD. Thus the role of IL-18 in the progression of PM still needs larger cohorts to be validated.

In conclusion, serum IL-18 was found to be elevated in DM patients and the level was particularly associated with disease activity and ILD complication in these patients. Thus, serum IL-18 may serve as a useful serological marker for DM disease activity and DM complicated with ILD.

\section{Declaration of conflicting interests}

The authors declared no conflicts of interest with respect to the authorship and/or publication of this article.

\section{Funding}

The authors received no financial support for the research and/or authorship of this article.

\section{REFERENCES}

1. Dalakas MC. Review: An update on inflammatory and autoimmune myopathies. Neuropathol Appl Neurobiol 2011;37:226-42.

2. Furst DE, Amato AA, lorga SR, Gajria K, Fernandes AW. Epidemiology of adult idiopathic inflammatory myopathies in a U.S. managed care plan. Muscle Nerve 2012;45:676-83.

3. Tucci M, Quatraro C, Dammacco F, Silvestris F. Increased IL-18 production by dendritic cells in active inflammatory myopathies. Ann N Y Acad Sci 2007;1107:184-92.

4. Dalakas MC. Pathophysiology of inflammatory and autoimmune myopathies. Presse Med 2011;40:237-47.

5. Asma M, Ghazala H, Kalia JS, Guzman MA. Idiopthic inflammatory myopathies: clinical approach and management. Front Neurol 2016;7:64.

6. Fathi M, Lundberg IE. Interstitial lung disease in polymyositis and dermatomyositis. Curr Opin Rheumatol 2005;17:701-6.

7. Isenberg DA, Allen E, Farewell V, Ehrenstein MR, Hanna MG, Lundberg IE, et al. International consensus outcome measures for patients with idiopathic inflammatory myopathies. Development and initial 
validation of myositis activity and damage indices in patients with adult onset disease. Rheumatology (Oxford) 2004;43:49-54.

8. Matsumoto S, Tsuji-Takayama K, Aizawa Y, Koide K, Takeuchi M, Ohta T, et al. Interleukin-18 activates NF-kappaB in murine T helper type 1 cells. Biochem Biophys Res Commun 1997;234:454-7.

9. Puren AJ, Fantuzzi G, Gu Y, Su MS, Dinarello CA. Interleukin-18 (IFNgamma-inducing factor) induces IL-8 and IL-1beta via TNFalpha production from nonCD14+ human blood mononuclear cells. J Clin Invest 1998;101:711-21.

10. Tucci M, Quatraro C, Dammacco F, Silvestris F. Interleukin-18 overexpression as a hallmark of the activity of autoimmune inflammatory myopathies. Clin Exp Immunol 2006;146:21-31.

11. Gono T, Kawaguchi Y, Sugiura T, Ichida H, Takagi $\mathrm{K}$, Katsumata $\mathrm{Y}$, et al. Interleukin-18 is a key mediator in dermatomyositis: potential contribution to development of interstitial lung disease. Rheumatology (Oxford) 2010;49:1878-81.

12. Bohan A, Peter JB. Polymyositis and dermatomyositis (first of two parts). N Engl J Med. 1975;292:344-7.

13. Bohan A, Peter JB. Polymyositis and dermatomyositis (second of two parts). N Engl J Med 1975;292:403-7.

14. American Thoracic Society; European Respiratory Society. American Thoracic Society/European Respiratory Society International Multidisciplinary Consensus Classification of the Idiopathic Interstitial Pneumonias. This joint statement of the American Thoracic Society (ATS), and the European Respiratory Society (ERS) was adopted by the ATS board of directors, June 2001 and by the ERS Executive Committee, June 2001. Am J Respir Crit Care Med 2002;165:277-304.

15. Kikuchi Y, Koarada S, Tada Y, Ushiyama O, Morito F, Suzuki N, et al. Difference in B cell activation between dermatomyositis and polymyositis: analysis of the expression of RP105 on peripheral blood B cells. Ann Rheum Dis 2001;60:1137-40.
16. Wong CK, Ho CY, Li EK, Lam CW. Elevation of proinflammatory cytokine (IL-18, IL-17, IL-12) and Th2 cytokine (IL-4) concentrations in patients with systemic lupus erythematosus. Lupus 2000;9:589-93.

17. De Rossi M, Bernasconi P, Baggi F, de Waal Malefyt R, Mantegazza R. Cytokines and chemokines are both expressed by human myoblasts: possible relevance for the immune pathogenesis of muscle inflammation. Int Immunol 2000;12:1329-35.

18. Shen H, Xia L, Lu J. Pilot study of interleukin-27 in pathogenesis of dermatomyositis and polymyositis: associated with interstitial lung diseases. Cytokine 2012;60:334-7.

19. Marie I, Hachulla E, Chérin P, Dominique S, Hatron PY, Hellot MF, et al. Interstitial lung disease in polymyositis and dermatomyositis. Arthritis Rheum 2002;47:614-22.

20. Labirua A, Lundberg IE. Interstitial lung disease and idiopathic inflammatory myopathies: progress and pitfalls. Curr Opin Rheumatol 2010;22:633-8.

21. Connors GR, Christopher-Stine L, Oddis CV, Danoff SK. Interstitial lung disease associated with the idiopathic inflammatory myopathies: what progress has been made in the past 35 years? Chest 2010;138:1464-74.

22. Gono T, Kawaguchi Y, Hara M, Masuda I, Katsumata Y, Shinozaki M, et al. Increased ferritin predicts development and severity of acute interstitial lung disease as a complication of dermatomyositis. Rheumatology (Oxford) 2010;49:1354-60.

23. Gono T, Kaneko H, Kawaguchi Y, Hanaoka M, Kataoka S, Kuwana M, et al. Cytokine profiles in polymyositis and dermatomyositis complicated by rapidly progressive or chronic interstitial lung disease. Rheumatology (Oxford) 2014;53:2196-203.

24. Ward PA, Hunninghake GW. Lung inflammation and fibrosis. Am J Respir Crit Care Med. 1998;157:S123-129.

25. Ward PA, Hunninghake GW. Lung inflammation and fibrosis. Am J Respir Crit Care Med 1998;157:123-9. 